\title{
Laurinda Leite, Luis Dourado, Ana S. Afonso and Sofia Morgado (Eds.), Contextualizing Teaching to Improve Learning: The Case of Science and Geography, Nova Science Publishers: New York, NY, 2017; 303 pp.: ISBN: 978-1-53611-845-2
}

Reviewed by MiHA SLAPNIČAR ${ }^{1}$

In recent years, there has been an increasing interest in contextualising teaching to improve learning (Leite, 2017). In the past two decades, several researchers have sought to prove that context-based learning approaches have had a strong influence on school science in several countries as a way to both stimulate students' interest and motivation and to provide more interconnected content knowledge (King, 2012). A useful definition applied in several approaches is that the context 'is the red thread along which the investigation of the issue in question develops' (Nentwig et al., 2007, p. 1441), and not a mere decoration at the begin-

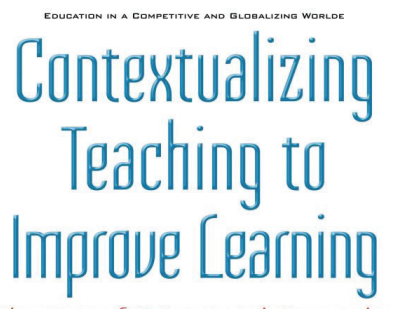

The Case of Science and Geography

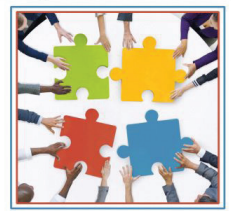

[aurinda [eite - [uís Dourado Ana S. Afonso - Sofia Morgado Editurs ning or in the end to illustrate something or motivate students. The context is the starting point from which the teaching proceeds and the foundational principle is that the learner will start from the context and then be aware of the content knowledge to understand the issue in question on a 'need-to-know'-principle (Bulte et al., 2006; adapted from Broman \& Parchmann, 2014). Recent developments have heightened the need for contextualising teaching to improve learning because context-based problems combine science content with contexts to make the problem more authentic and relevant; they require complex thinking and higher levels of scientific literacy (Hofstein et al., 2011).

Contextualising Teaching to Improve Learning, The Case of Science and Geography includes contributions by authors from various backgrounds, theorists, and practitioners. This book is organised into three parts. In analysing

1 Faculty of Education, University of Ljubljana, Slovenia; miha.slapnicar@pef.uni-lj.si. 
the contextualisation of teaching, researchers explain the significance of the relevance of science and geography knowledge for citizenship (Part 1, five chapters), approaches to improving contextualised science and geography learning (Part 2, six chapters), and curriculum materials and context-based learning (Part 3, five chapters).

In Chapter 1, Linn, Tan, Lim, and Teng note the relevance of biological knowledge for citizenship from a Singaporean perspective. This paper examines the significance of the global community in the rise of scientific grounding in biology. The authors suggest that global citizenship education must take into account the context of biological knowledge, which includes the pressing issues of food security, nutrition, biodiversity decline, and climate change.

In Chapter 2, Parchmann, Blonder, and Broman review a key aspect of chemistry, which is related to every material, question, and topic. Chemical reactions take place in every living organism, in the environment, and in the industrial production of all the different products people use; however, at the same time, the term 'chemistry' still has a negative connotation for many laypersons. In this paper, authors attempt to defend the view that educational links between contexts and the multi-perspective facets of chemistry aim to develop a better foundation for citizenship and responsible research and innovation.

Orion, in Chapter 3, describes a review of the earth science contents. A primary concern of his thesis is that extensive evidence-based data prove beyond any doubt that schools can realise the high relevance potential of all aspects of earth science education. This paper seeks to explain the problem that encouraging findings are not echoed in educational systems throughout the world.

Chapter 4, entitled 'The relevance of geography for citizenship education' (author: David Lambert) gives an account of the relationship between three important ideas: (1) citizenship, (2) education and (3) geography. The chapter opens up many arguments and introduces a capabilities approach as a framework to understand the purpose of geography in education when conceived as powerful knowledge.

The aim of Chapter 5 is to provide a conceptual, theoretical framework based on arguments that physics permeates the life of human beings and that learning physics is a citizen's right. The author Moreira presents different topics (e.g., knowledge and competences, meaningful learning, problem-situations, concepts and conceptualisation, models and modelling, criticality and dialogicity, and critical, meaningful learning) that are necessary for physics teaching if it is to be geared to citizenship instead of being directed at success on testing.

Chapter 6 is the first chapter of the second part of this book. Its authors, Behrendt and Machtmes, argue that promoting experiences in outdoor 
environments is an essential component in the school system, and plays a key role in enhancing interest and engaging learning. This paper reviews the research conducted on the brief history of experiential learning, informal and non-formal learning, interest, outdoor learning, and outdoor methodology. In the end, it is hoped that not only has learning occurred but that each learner has discovered an interest in some aspect of the experience.

Chapter 7, entitled 'Making the most of the news: approaches to using media-based learning contexts' (author: Billy McClune), focuses on news media and news reports that stimulate scientific and geographic ways of thinking. This study provided a significant opportunity to advance the understanding of the nature of media reporting of issues with scientific and geographical components. The findings should make a significant contribution to the field of the explorability of the characteristics of effective curricular planning and classroom practice and provide exemplars of good practice to illustrate opportunities for multidisciplinary approaches to using news media in the classroom.

Chapter 8 analyses the results of the German course ('Inquire for teacher students'), whose goal is to promote inquiry-based science education in the context of two major challenges of the $21^{\text {st }}$ century: biodiversity loss and climate change. The findings of this research make several contributions to the current literature. First, context-specific subject knowledge to analyse the complex Helgoland lobster syndrome; second, systems thinking based on the syndrome approach; third, the teacher candidates' self-estimation in respect to their systems thinking abilities.

Leite, Dourado, Afonso, and Morgado, in Chapter 9, focus on contextbased science education and, in particular, on four variations of problem-based learning that may promote such education: place-based learning, problembased learning, project-based learning, and design-based learning. After each of these approaches is explained, their distinguishing features are highlighted, and they are related to different models of contextualisation.

Chapter 10 aims to provide those involved in science education with some ideas and guidelines, from a research or a training perspective, that have been developed through research on contextualisation and on Science-TechnologySociety (STS) approaches in different parts of the world and the way they relate to each other. The most obvious finding to emerge from this research is that contextualised science teaching, through STS approaches, can improve the comprehension of the natural world and its potential for creating new goods.

The final chapter in the second part of the book (author: Mariana G. Hewson) talks about contextualising science teaching in southern Africa using indigenous knowledge. The author describes how to generate a teaching 
approach (Tailored Teaching (TT)) that can serve to contextualise science learning. The TT approach, based on the theory of learning as conceptual change, is one possible approach to making a difference in bringing science to students with indigenous backgrounds.

As previously mentioned, Part 3 presents research efforts in the analysis of the content of the curriculum materials and context-based learning. In Chapter 12, as the first chapter in Part 3, the authors describe examples of tasks that were designed to make science relevant to pupils by offering them a challenging learning environment and showing what pupils have learnt by participating in the tasks. They were developed within the European projects PARSEL (Popularity and relevance of science education for scientific literacy) and SAILS (Strategies for assessment of inquiry learning in science) and were tested in the countries that participated in the projects.

One of the more significant findings to emerge from a study in Chapter 13 provides insights into the potential of geotechnologies for teaching and learning. The impact of current geotechnologies, geomedia, and geodata on everyday life was also shown. The purpose of the current study is to provide learners not only with competences to use geotechnologies, but to make sense of these options and to gain profit from their added value.

The study in chapter 14, entitled 'Case-based curricula materials for contextualised and interdisciplinary biology and geology learning' (authors: Clara Vasconcelos and Joana Faria), has found that geology is generally taught together with other sciences, with which it constitutes one only discipline. The development of interdisciplinary curricula was necessary to bridge the gap between the sciences involved in such disciplines. The most prominent finding to emerge from this study is the benefits of using geological materials to treat health problems.

The study presented in chapter 15 (author: Iztok Devetak) systematically reviews the data for context-based teaching material and learning chemistry, aiming to prove that context-based learning in chemistry should be one of the major concerns of policymakers in any given society. The central thesis of this paper is that there has been an attempt to develop context-based learning further and to apply it in the school environment with the aid of additional teaching and learning material. This study examines the significance of Context-Based Chemistry Material (CBCM) in the rise of teaching and learning chemistry.

The authors of chapter 16, Neslihan Ültay and Eser Ültay, report on an analysis of some critical points on evaluating context-based teaching materials given by two different studies. Ten critical points are argued via a sample 
classroom practice of context-based teaching materials, which include the preparation of such materials, and finally evaluating them in the classroom.

In conclusion, we can say that contextualising teaching is an indispensable part of the educational process, not just in science and geography, as described in this book, but also in other school subjects. The current findings add to a growing body of literature on raising awareness for the contextualised teaching issue and shed some light on how teachers can use from students' complicated and interconnected real worlds to help them learn more and better authentic science and geography. The relevance of interdisciplinary teaching and learning science or geography is clearly supported by the current findings. Returning to the thesis posed at the beginning of this review, it is now possible to state that teaching science, geography, and other subjects to students that feel that they have many more interesting things to do and that do not have a need to know feeling towards those disciplines is not an easy task.

\section{References}

Broman, K., \& Parchmann, I. (2014). Students' application of chemical concepts when solving chemistry problems in different contexts. Chemistry Education Research and Practice, 15(4), 516-529. Hofstein, A., Eilks, I., \& Bybee, R. (2011). Societal issues and their importance for contemporary science education. A pedagogical justification and the state-of-the-art in Israel, Germany, and the USA. International Journal of Science and Mathematics Education, 9(1), 1459-1484. King, D. (2012). New perspectives on context-based chemistry education: using a dialectical sociocultural approach to view teaching and learning. Studies in Science Education, 48(1), 51-87. Leite, L. (2017). Why should contextualized teaching be a matter for educational concern? In L. Leite, L. Dourado, A. S. Afonso, \& S. Morgado (Eds.), Contextualizing teaching to improve learning: The case of science and geography (pp. xx-xxv). New York, NY: Nova Science Publishers.

Leite, L., Dourado, L., Afonso, A. S., \& Morgado, S. (Eds.) (2017). Contextualizing teaching to improve learning: The case of science and geography. New York, NY: Nova Science Publishers.

Nentwig, P., Demuth, R., Parchmann, I., Grasel, C., \& Ralle, B. (2007). Chemie im Kontext: Situated learning in relevant contexts while systematically developing basic chemical concepts. Journal of Chemical Education, 84(9), 1439-1444. 